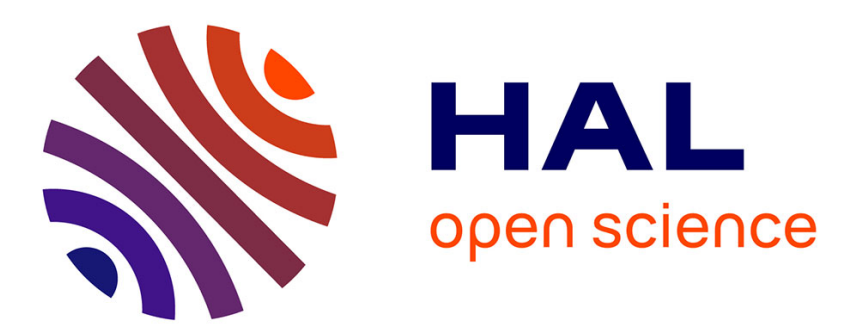

\title{
An Extended Circular Supply Chain Model Including Repurposing Activities
}

Asiye Kurt, Van-Dat Cung, Fabien Mangione, Mario Cortes-Cornax, Agnès

Front

\section{- To cite this version:}

Asiye Kurt, Van-Dat Cung, Fabien Mangione, Mario Cortes-Cornax, Agnès Front. An Extended Circular Supply Chain Model Including Repurposing Activities. ICCAD 2019 - 3rd International Conference on Control, Automation and Diagnosis, Jul 2019, Grenoble, France. pp.1-6, 10.1109/ICCAD46983.2019.9037929 . hal-02528941

\section{HAL Id: hal-02528941 https://hal.science/hal-02528941}

Submitted on 22 Jun 2021

HAL is a multi-disciplinary open access archive for the deposit and dissemination of scientific research documents, whether they are published or not. The documents may come from teaching and research institutions in France or abroad, or from public or private research centers.
L'archive ouverte pluridisciplinaire HAL, est destinée au dépôt et à la diffusion de documents scientifiques de niveau recherche, publiés ou non, émanant des établissements d'enseignement et de recherche français ou étrangers, des laboratoires publics ou privés. 


\section{An Extended Circular Supply Chain Model Including Repurposing Activities}

\author{
Asiye Kurt, Van-Dat Cung, Fabien Mangione \\ Univ. Grenoble Alpes, CNRS, Grenoble INP*, G-SCOP \\ * Institute of Engineering Univ. Grenoble Alpes \\ 38000, Grenoble, France \\ name.surname@grenoble-inp.fr
}

\author{
Mario Cortes-Cornax, Agnès Front \\ Univ. Grenoble Alpes, CNRS, Grenoble INP*, LIG \\ * Institute of Engineering Univ. Grenoble Alpes \\ 38000, Grenoble, France \\ name.surname@univ-grenoble-alpes.fr
}

\begin{abstract}
Repurposing concerns the reuse of products or materials for a different purpose from its original function, creating material flows between distinct supply chains. This circular economy activity reduces waste and creates new value. It remains scarcely explored in the literature and often limited to a small scale in practice. This paper proposes an extended approach to model circular supply chains considering repurposing as a firstclass citizen. A hierarchical framework of the principal circular economy activities including repurposing activities is introduced first. The framework is then integrated into an extended model that conceptualizes the circular supply chain structure in a generic way. The proposed model allows to represent and analyze the material flows as well as the activities of circular supply chains.
\end{abstract}

Keywords- Circular Economy, Supply Chain, Repurposing, Modelling Framework, Material Flows

\section{INTRODUCTION}

The circular economy is defined as "a regenerative system in which resource input and waste, emission, and energy leakage are minimized by slowing, closing, and narrowing material and energy loops. This can be achieved through longlasting design, maintenance, repair, reuse, remanufacturing, refurbishing, and recycling" [1]. The circular economy concept has received attention worldwide in the latter years [2]. In academia, the number of publications has increased rapidly since 2014 [1]. In industry, alongside the adoption of circular economy principles by existing firms, new players that execute circular economy activities as a core business have emerged, such as $\mathrm{RLG}^{1}$ (worldwide) or $\mathrm{SNAM}^{2}$ in France.

The circular economy is not only concerned with environmental issues, but it also focuses on economic strategy [3]. Indeed, the circular economy aims to apply these principles by maximizing savings in energy, labor and capital inputs [4].

Govindan and Hasanagic [5] emphasize the need for research on the implementation of the circular economy from the supply chain perspective. The authors highlight the impact of the supply chain in the organizations' performance and define the circular economy as a vital strategy for supply chain innovation.

Supply chain management is a well-established research area, with many definitions. In this work we refer to the definition proposed by Eng [6] and reformulated by Ahi and Searcy [7]: "Managing the inputs of goods or services including

Sponsor: "This research is supported by the French National Research Agency under the "Investissements d'avenir" program (ANR-15-IDEX-02) through the Cross Disciplinary Program CIRCULAR"

https://www.rev-log.com/

https://www.snam.com/ a range of activities not only within a single department in an organization but also from different departments and outside the organization, for final users from procurement of raw materials through to the end of the products' useful life." Based on the latter definition, this work focuses on the activities and material flows of a circular supply chain, from raw material extraction to the end of life of the product, including its components or material.

The activities proposed to implement circular economy principles have been widely studied in literature by researchers from various domains such as waste management, product recovery management, closed loop supply chains, etc. [8]-[10]. Repurposing concerns the reuse of products or materials for a new purpose different from its original function [9]. This circular economy activity creates flows between distinct supply chains. It also adds value to used products, complementing the other circular economy activities (reuse, remanufacturing, recycling, etc.) Thus, it creates new potential for the implementation of the circular economy. However, this activity remains scarcely explored in the literature and limited to a small scale in practice. Indeed, Brissaud and Zwolinski [11] highlight that repurposing-based circular production systems raises new challenges on supply chain management and optimization.

The aim of this work is to explore repurposing activities with a supply chain perspective and integrate this concept into a generic model in order to analyze and model the supply chain activities as well as the circular flows between them. To do so, we firstly conducted a literature review to explore how circular supply chains are defined and characterized in the literature. Then, based on the analysis of different approaches, we propose an extended circular supply chain model in order to conceptualize this complex structure.

The paper is structured as follows. Section 2 presents the existing literature and highlights the main flows of a circular supply chain structure as well as circular economy activities generating these flows. Section 3 describes a hierarchical framework of circular economy activities that includes a detailed partition of the repurposing activities. In section 4 an extended model of Circular Supply Chains is proposed, which relies on the hierarchical framework. Section 5 concludes the paper and highlights discussions about the results and future perspectives. 


\section{LITERATURE REVIEW}

This section presents the definition of the circular supply chain as well as its related concepts in literature. Then, the different circular flows in the context of circular supply chains are determined and classified. Finally, the activities that implement the circular economy principles and support circular flows are investigated.

\section{A. Circular Supply Chains and Related Concepts}

Several recent works investigated the theoretical bridge between the circular economy and the supply chains. Geissdoerfer et al. [12] proposed a framework of circular business models and circular supply chains in order to integrate them into sustainable development. They defined circular supply chain management as "the configuration and coordination of the supply chain to close, narrow, slow, intensify and dematerialize resource loops". Furthermore, Masi et al. [13] conducted a systematic literature review to explore supply chain configurations in the circular economy. The authors identified three supply chain configurations: Eco-Industrial Parks, Environmental, Sustainable and Green Supply Chains, and Closed Loop Supply Chains. In the same line, Batista et al. [14] proposed a circular supply chain archetype from four sustainable supply chain narratives: reverse logistics, green supply chains, sustainable supply chain management, and closed loop supply chains. These related concepts are explained below.

Reverse Logistics (RL) is defined as "the process of planning, implementing and controlling the efficient, effective inbound flow and storage of secondary goods and related information, opposite to the traditional supply chain directions for the purpose of recovering value and proper disposal" [15]. The term of recovering value refers to product recovery strategies. RL starts from the collection of end-of-life products from customers followed by a sorting process and reprocessing activities such as prepare for reuse, remanufacturing, recycling and also disposal activities [16].

The integration of forward and reverse flows brings out the concept of Closed Loop Supply Chain (CLSC) [17]. This structure has two missions: first, to respond to customers' demands (as a classic supply chain) and second, to collect the end of life products and maintain them in the best way [17].

Green Supply Chain Management (GSCM) is concerned with sharing environmental responsibility between organizations [18]. Sustainable Supply Chain Management (SSCM) extends this approach by adopting the social and economic dimension of sustainability [7]. Some of the main concepts of GSCM and SSCM are green design, resource saving, green purchasing, reverse logistics, as well as product reuse, remanufacturing and recycling [18], [19].

Closed Loop Supply Chains and reverse logistics as well as GSCM and SSCM approaches provide the reduction of waste and keep products in use, which are the key principle of the circular economy. Moreover, the models that represent material flows and activities of a supply chain exist in these research domains [8], [20]-[22]. However, these approaches are insufficient, as these works only focus on the flow of one product and not consider by-products and waste as a useful product in order to reduce waste [14]. Indeed, the flows of waste

and by-products should be taken into account in a circular supply chain. In addition, these approaches do not consider the open flows of by-products and waste across distinct industries [14]. As we already mentioned, our focus on material flows and on the structure of supply chains. Therefore, the main flows of circular supply chains and the activities that generate the circular flows are investigated in the next sections.

\section{B. Circular Flows of a Supply Chain}

A circular supply chain structure is defined as a combination of open and closed loops from a material flow perspective [14], [23]:

- Closed loops refer to the integration of forward and reverse flows. In closed loop systems, end-of-life products turn back to supply chain through reusing, repairing, refurbishing, remanufacturing and recycling activities. These activities provide the valorization of waste and minimize the use of raw materials by reprocessing used products.

- Open loops consist of the cascaded material flows. 'The power of cascaded use' (Fig. 1-b), which is a source of value creation in the circular economy [4], refers to material flows across different supply chains. Cascaded use of materials generates the open loops in the circular supply chain.

We divide the open loops into two sub-categories: open loops at the production stage and open loops at the end-of-life stage. The first category concerns the engagement between traditionally separate organizations called Industrial Symbiosis [24]. In such collaboration, the waste or the by-products of a production process can be used as input for other processes. Here, a material flow across manufacturers can be observed. Industrial Symbiosis is also one of the core topics of circular economy [25] and is defined as a circular economy business model by scholars [26].

In addition to open flows of by-products and wastes across distinct industries at the production stage, end-of-life products can create an open loop across industries. In this study, we focus on repurposing activities that provide open flows at the end-oflife stage. As mentioned before, repurposing refers to the use of a used product for new purposes [9]. It creates open material flows to distinct supply chains. For example, repurposing smartphones in car parking meter [27], repurposing electric vehicle batteries in energy storage systems [28] or repurposing used clothes as cleaning clothes [2].

\section{Activities generating Circular Flows}

In order to develop an extended model, the activities that create open and closed loops are investigated. Since one of the

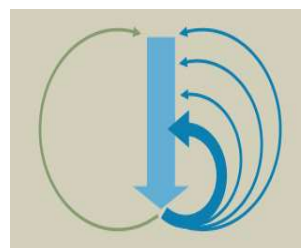

Fig. 1-a. The power of the inner circle [4]

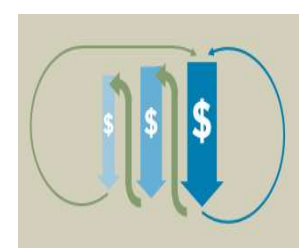

Fig. 1-b. The power of cascaded use [4] 
principles of the circular economy is to design out the waste and valorize the product or the material that could be a waste [4], we investigated product recovery and waste management activities (i.e., reuse, remanufacturing, recycling, etc. Such activities that generate the open and closed loops of circular supply chains have been widely studied in literature. Researchers in various domains such as Waste Management, Reverse Logistics, and Closed-Loop Supply Chain Management have contributions in this domain For instance, Reike et al. [10] named these activities as $\mathrm{R}$ imperatives. The authors indicate that while the $3 \mathrm{R}$ (Reduce, Reuse and Recycle) framework is an accepted notion of the circular economy, "more nuanced hierarchies" with shorter loops such as refurbish, remanufacture and repurpose need to be considered in order to recover the highest value from products. We show that the repurposing term is still not consensual, in particular in the way that it is placed in the different frameworks.

In the literature, there are several frameworks containing from 3 to $10 \mathrm{R}$ imperatives [10]. Some frameworks have a hierarchical structure, where the activities are ranked according to environmental performance [29]. Also, the logic behind these hierarchies could be explained by the principle of 'the power of the inner circle' (Fig. 1-a): the tighter the circle is, the less a product has to be changed during reprocessing, and therefore, the more potential savings on material, labor, energy, and capital will be obtained [4], [23]. Table 1 proposes a comparison of several frameworks from the literature.

Table 1 shows that repurposing appears at different places in the hierarchies. For instance, Sihvonen \& Ritola [9] place repurposing after direct reuse. The authors define repurposing as "Using same product for new purposes without any adjustment" and merge direct reuse, repurposing repair, refurbishing, remanufacture and resynthesize under the title of 'reuse'. In other frameworks [10], [30], [31], repurposing is placed after remanufacturing. We note that the industrial symbiosis approach that generates open loops at the production level is not presented in these frameworks.

As discussed, the repurposing activities that generate open loops at the end-of-life stage remain barely explored among scholars and industrials. Today, there are few applications of this activity. Therefore, it is challenging to emplace repurposing in the circular economy hierarchy. Repurposing activities have been applied in small scale such as repurposing wooden pallets and tires as furniture. Adopting this approach in an industrial scale could be a new opportunity to obtain the highest value from a used product. Therefore, considering repurposing as a firstclass citizen in a circular economy framework is important in order to clarify and exploit it.

\section{HIERARCHICAL FRAMEWORK FOR CIRCUlAR ECONOMY ACTIVITIES}

This section presents our proposal for an extension of the hierarchical framework from [30] in order to place repurposing activities. Considering 'the power of the inner circle' principle we can state that repurposing is more circular than recycling. Since the recycling activity recovers only materials from products, destroys the added value of the product, while repurposing preserves added value [32]. Also, considering the environmental performance of activities, repurposing is more environmental friendly than recycling. For example, repurposing electric vehicle batteries postpones recycling of $\mathrm{Li}$ ion batteries, which is an environmentally hazardous and costly process [33]. However, considering the environmental performance or the principle of 'the power of the inner circle' [4] we think that it is not possible to compare the circularity of repurposing activities with reuse, remanufacturing, refurbishing activities as long as the required work, environmental and economic aspects of repurposing depends on the characteristics and design of products.

TABLE I.

Circular ECONOMY ACTIVITIES Framewroks

\begin{tabular}{|c|c|c|c|c|c|c|c|c|c|c|c|c|}
\hline European & \multicolumn{3}{|c|}{ Prevention } & \multicolumn{6}{|c|}{ Preparing for Reuse } & \multirow{2}{*}{ 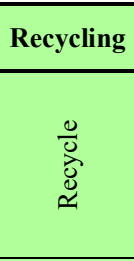 } & \multirow{2}{*}{ 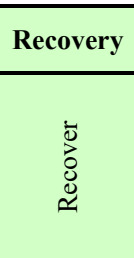 } & \multirow[t]{2}{*}{ Disposal } \\
\hline $\begin{array}{c}\text { Potting et al. } \\
{[30]}\end{array}$ & 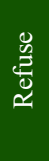 & 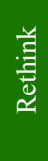 & 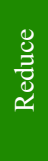 & $\begin{array}{l}0 \\
\mathscr{E} \\
\simeq\end{array}$ & & $\begin{array}{l}\text { 䒕 } \\
\stackrel{\tilde{Q}}{\simeq}\end{array}$ & $\begin{array}{l}\frac{5}{n} \\
\frac{0}{2} \\
\frac{0}{0} \\
\simeq\end{array}$ & 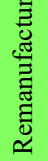 & 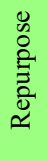 & & & \\
\hline $\begin{array}{c}\text { Sihvonen \& } \\
\text { Ritola }[9]\end{array}$ & & & 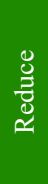 & 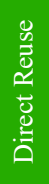 & 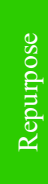 & 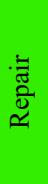 & $\begin{array}{l}\frac{5}{n} \\
\frac{0}{0} \\
\frac{2}{0} \\
\simeq\end{array}$ & 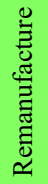 & 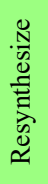 & 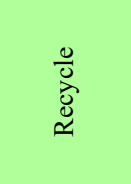 & $\begin{array}{l}\overline{0} \\
\dot{0} \\
0 \\
\simeq\end{array}$ & \\
\hline $\begin{array}{c}\text { Reike et al. } \\
{[10]}\end{array}$ & $\begin{array}{l}0 \\
\stackrel{2}{2} \\
\stackrel{2}{0}\end{array}$ & & $\begin{array}{l}0 \\
\stackrel{0}{0} \\
\approx \\
\approx\end{array}$ & $\begin{array}{l}0 \\
\mathscr{E} \\
\simeq\end{array}$ & & 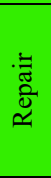 & 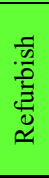 & 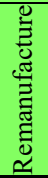 & 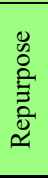 & $\begin{array}{l}\text { यँ } \\
\text { তু } \\
\simeq\end{array}$ & 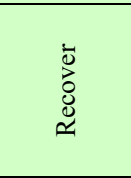 & $\begin{array}{l}\text { 胃 } \\
\text { ¿ }\end{array}$ \\
\hline $\begin{array}{c}\text { van Buren et } \\
\text { al. }[31]\end{array}$ & $\begin{array}{l}0 \\
\stackrel{0}{0} \\
\stackrel{2}{0}\end{array}$ & & 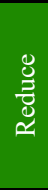 & $\begin{array}{l}0 \\
0 \\
\tilde{D} \\
\simeq\end{array}$ & & $\begin{array}{l}\stackrel{\bar{\pi}}{0} \\
\stackrel{0}{\simeq}\end{array}$ & 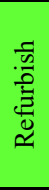 & 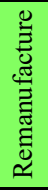 & 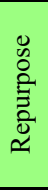 & $\begin{array}{l}\text { 0. } \\
\text { ঠूँ } \\
\simeq\end{array}$ & $\begin{array}{l}\overline{0} \\
\overrightarrow{0} \\
0 \\
\simeq\end{array}$ & \\
\hline
\end{tabular}


In order to emplace repurposing in our framework, the activities direct reuse, repair, refurbishing, remanufacturing are included under the title 'reuse', as in the hierarchy proposed by the European Commission [29]. We assume that repurposing and reuse are at the same circularity level (Fig. 2-a). Reuse and repurposing activities differ in the direction of the material flows. Repurposing activities generate open flows (i.e., different supply chain), while reuse activities generate closed flow (i.e., same supply chain).

Fig. 2-b gives a more detailed view of reuse and repurposing activities of Fig. 2-a. Since the activities of reuse are already prioritized in the literature as direct reuse, repair, refurbish and remanufacture, we create a set of repurposing activities with a similar structure. This level of detail is not valid for non-modular products such as glass and textile, since the repair, refurbishing, and remanufacturing activities require a disassembly. This fact justifies the grouping of aforementioned activities in Fig. 2-a.

We assume that there is no need to differentiate the activities where the used products turn into materials or energy with the open or closed loop distinction. Indeed, recycling and recovering could be considered both at the same time without changing the process. For instance, the plastic recycled from bottles (the output flow of recycling activity of plastic bottles) could be reused both for plastic bottles (closed loop) and for insulation (open loop).

Table 2 summarizes the definition of the activities found in the literature used in our framework concerning reuse (white lines). We rely on them to introduce the new repurposing activities (grey lines). These activities composing the framework are the basis for our extended circular supply chain model presented in the next section.

\section{EXTENDED MOdEl FOR CIRCUlar SuPPly CHAINS}

Based on the hierarchical framework and the model of Thierry et al. [8], an extended model is proposed in order to conceptualize the Circular Supply Chains structure. In this model, closed loops and open loops at the end-of-life stage are represented. This results in a multi-chained supply chain structure as a combination of distinct supply chains, as illustrated in Fig. 3.
Relying on the aforementioned definition of supply chain management [6] (Section 1), this model contains activities and material flows of circular supply chains. It includes two classic supply chain structure (represented by white blocks) of two different products. We note that, at the end of its life, the first product or its components could be used to produce the second product by repurposing activities. Classic supply chains start with material extraction, then manufacturing and distribution activities and end with the use. This structure is followed by the collection activity, which encompasses the product sorting process.

The collection activity consists of the pick-up and transportation of used products [16]. During sorting activity, the collected products are inspected in order to decide how they can be reprocessed. Sorting could involve disassembly in order to test and reprocess parts or modules of a product. Note that the activities presented in the hierarchical framework (Fig. 2-a and Fig. 2-b) proposed in section 3, represent the reprocessing activities that follow the sorting. The circularity of activities is represented by texture gradient (the darker the activity is, the more is the contributions to the circularity of the supply chain).

As shown in Fig. 3, there are two kinds of material flows in our extended model of supply chain: direct flows and reverse flows. Direct flows represent the material flows between the activities of the classical supply chain. Reverse flows concerns material flows of used product. Reverse flows generated by reuse activities return to the original classic supply chain in distinct points, as in the work of Thierry et al. [8]. These reverse and direct flows constitute closed loops. Material flows of repurposing activities integrate into the classic supply chain of the second product. The reverse flows between customers and the classical supply chain of the second product constitute openloops at the end-of-life stage.

The energy output of recovering activity flows to waste-toenergy supply chains, which are not included in our model. Moreover, the term of ecosphere taken from Industrial Ecology is used [34] to highlight the material flows between environment and industrial systems. The ultimate wastes are supposed to return to ecosphere during landfilling activity.

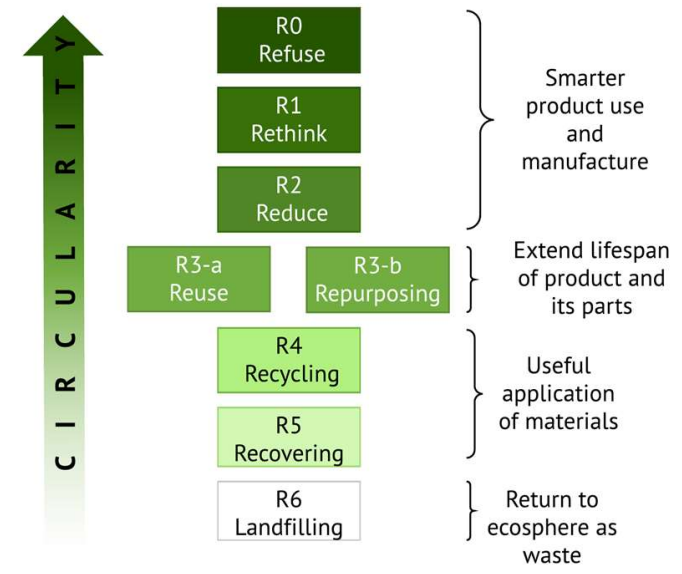

Fig. 2-a. Hierarchical Framework of circular economy strategies extending [30]

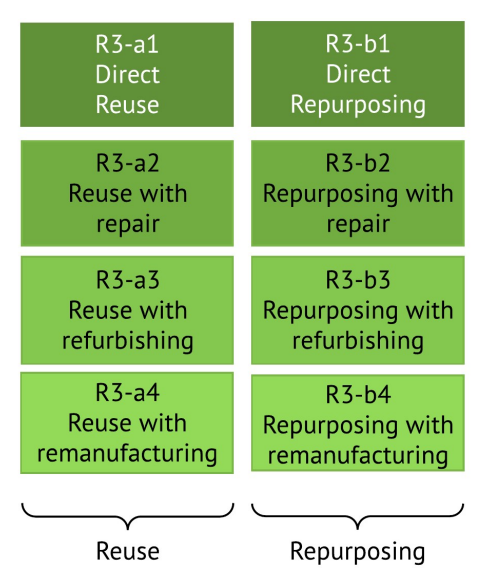

Fig. 2-b. Detailed representation of reuse and repurposing strategies 
CHARACTERISTICS OF CIRCULAR ECONOMY ACTIVITIES

\begin{tabular}{|c|c|}
\hline $\begin{array}{l}\text { Circular Economy } \\
\text { Activity }\end{array}$ & Definition \\
\hline R3-al Direct Reuse & Reuse the product by minor changes \\
\hline $\begin{array}{l}\text { R3-b1 Direct } \\
\text { Repurposing } \\
\end{array}$ & $\begin{array}{l}\text { Reuse the product in different function by minor } \\
\text { changes }\end{array}$ \\
\hline $\begin{array}{l}\text { R3-a2 Reuse with } \\
\text { Repair }\end{array}$ & $\begin{array}{l}\text { Replace the defective parts of a product, in order } \\
\text { to bring it a specific quality and reuse for the same } \\
\text { purpose [8]. }\end{array}$ \\
\hline $\begin{array}{l}\text { R3-b2 Repurposing } \\
\text { with repair }\end{array}$ & $\begin{array}{l}\text { Replace the defective parts of a product, in order } \\
\text { to bring it a specific quality and reuse for new } \\
\text { purposes. }\end{array}$ \\
\hline $\begin{array}{l}\text { R3-a3 Reuse with } \\
\text { refurbish }\end{array}$ & $\begin{array}{l}\text { Replace the critical parts of a product modules, in } \\
\text { order to bring them a specific quality for the same } \\
\text { purposes [8]. }\end{array}$ \\
\hline $\begin{array}{l}\text { R3-b3 Repurposing } \\
\text { with refurbish }\end{array}$ & $\begin{array}{l}\text { Replace the critical parts of product modules, in } \\
\text { order to bring them a specific quality for new } \\
\text { purposes. }\end{array}$ \\
\hline $\begin{array}{l}\text { R3-a4 Reuse with } \\
\text { remanufacture }\end{array}$ & $\begin{array}{l}\text { Replace a big amount of parts of a product, in } \\
\text { order to bring it to a like-new quality and reuse for } \\
\text { the same purpose [8]. }\end{array}$ \\
\hline $\begin{array}{l}\text { R3-b4Repurposing } \\
\text { with remanufacture }\end{array}$ & $\begin{array}{l}\text { Replace a big amount of product parts, in order } \\
\text { to bring it to a like-new quality for new purposes. }\end{array}$ \\
\hline R4 Recycling & $\begin{array}{l}\text { Transform the product into materials for new } \\
\text { products. }\end{array}$ \\
\hline R5 Recovering & $\begin{array}{l}\text { Incineration of materials with energy recovery } \\
{[30]}\end{array}$ \\
\hline R6 Landfilling & $\begin{array}{l}\text { Dispose the product into ecosphere as an ultimate } \\
\text { waste. }\end{array}$ \\
\hline
\end{tabular}

\section{DISCUSSION AND CONCLUSION}

The repurposing, which is an interesting circular economy activity remains often limited to small scale and unexplored in the literature. This study aimed to explore repurposing, with a supply chain perspective and propose an extended model of circular supply chains including this activity. We investigated the open and closed circular flows as well as activities of a circular supply chain and included both perspectives in the proposed model.

Firstly, a hierarchical framework of circular economy activities considering different levels of repurposing is proposed based on the work of Potting et al. [30] and the principle of 'the power of the inner circle' [4]. This hierarchy also considers the aforementioned open loops at the production stage. This hierarchical framework is valid for treatment of end of life products as well as material exchange among different industries, namely Industrial Symbiosis, which could be categorized in our framework as direct repurposing of byproducts or wastes.

This framework could also be a basis to determine the level of circularity of organizations. However, note that the potential savings on material, labor, energy, and capital of a reprocessing activity depend on the characteristics of the product. Therefore, in order to propose an evaluation method, a more detailed approach depending on processes and products is needed.

Secondly, based on this hierarchical framework and the work of Thierry et al. [8], an extended model of circular supply chain is proposed. This model involves circular economy activities including repurposing and the material flows generated by these activities. This results in a multi-chained supply chain structure as a combination of distinct supply chains. The model could help to visualize and design specific supply chain structures by choosing the appropriate activities.

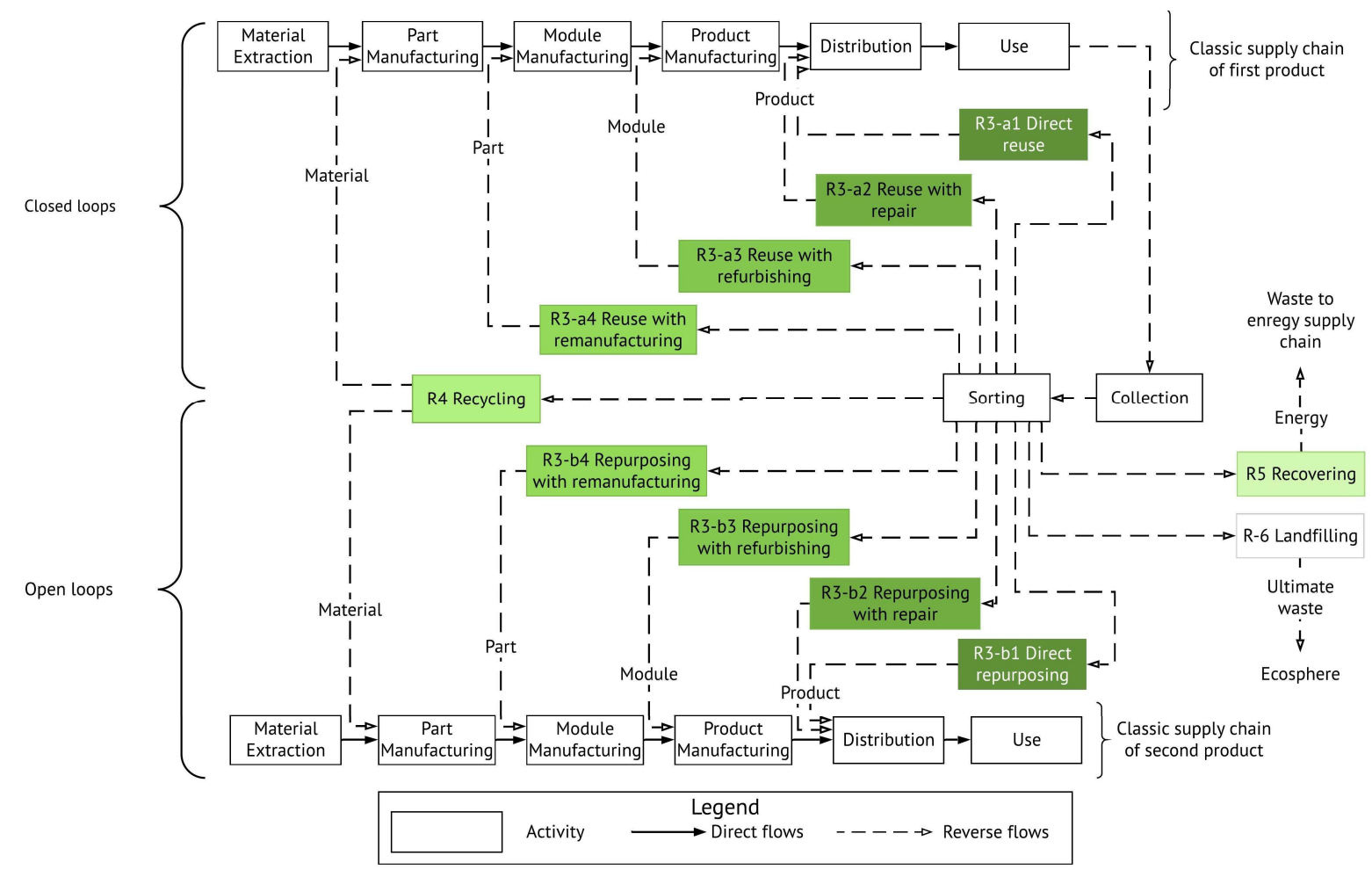

Fig. 3. Extended model of circular supply chain 
For simplicity reasons, this model does not contain open flows at production stage. Besides, in order to have a correct and simple model, the activities of the model could be gathered or separated since different product types require different level of details.

For future works, based on the extended model, new methods to assess the circularity of supply chains could be developed. Since the model shows material flows, this model could be a basis to setup circularity indicators based on material flows. Furthermore, this model could be integrated into a continuous improvement method, in order to help industries in the transition to more circular supply chains. Moreover, dimensions such as product quality and actor (i.e. which companies are in charge of which activities of the circular supply chains) could be integrated into our model. For validation of our model, applications on industrial cases from distinct sectors are needed.

\section{REFERENCES}

[1] M. Geissdoerfer, P. Savaget, N. M. P. Bocken, and E. J. Hultink, "The Circular Economy - A new sustainability paradigm?," J. Clean. Prod., vol. 143, pp. 757-768, 2017.

[2] Ellen MacArthur Foundation, "Towards the Circular Economy Vol.3: Accelerating the scale-up across global supply chains," 2014.

[3] Z. Yuan, J. Bi, and Y. Moriguichi, "The circular economy: A new development strategy in China," J. Ind. Ecol., vol. 10, no. 1-2, 2006.

[4] Ellen MacArthur Foundation, "Towards the Circular Economy," Ellen MacArthur Found., vol. 1, pp. 1-96, 2013.

[5] K. Govindan and M. Hasanagic, "A systematic review on drivers, barriers, and practices towards circular economy: a supply chain perspective," Int. J. Prod. Res., vol. 56, no. 1-2, pp. 278-311, 2018.

[6] T. Eng, "The Influence of a Firm 's Cross-Functional Orientation on Supply Chain Performance," vol. 41, no. 4, pp. 4-16, 2005.

[7] P. Ahi and C. Searcy, "A comparative literature analysis of definitions for green and sustainable supply chain management," J. Clean. Prod., vol. 52, pp. 329-341, 2013.

[8] M. Thierry, M. Salomon, J. Van Nunen, and L. Van Wassenhove, "Strategic Issues in Product Recovery Management," Calif. Manage. Rev., vol. 37, no. 2, pp. 114-136, 2012.

[9] S. Sihvonen and T. Ritola, "Conceptualizing ReX for aggregating endof-life strategies in product development," in Procedia CIRP, 2015, vol. 29, pp. 639-644.

[10] D. Reike, W. J. V. Vermeulen, and S. Witjes, "The circular economy: New or Refurbished as CE 3.0? - Exploring Controversies in the Conceptualization of the Circular Economy through a Focus on History and Resource Value Retention Options," Resour. Conserv. Recycl., vol. 135 , pp. 246-264, 2018.

[11] D. Brissaud and P. Zwolinski, "The Scientific Challenges for a Sustainable Consumption and Production Scenario: The ircular Reuse of Materials for the Upgrading and Repurposing of Components," in Procedia CIRP, 2017, pp. 663-666.

[12] M. Geissdoerfer, S. N. Morioka, M. M. de Carvalho, and S. Evans, "Business models and supply chains for the circular economy," $J$. Clean. Prod., vol. 190, pp. 712-721, 2018.

[13] D. Masi, S. Day, and J. Godsell, "Supply Chain Configurations in the Circular Economy: A Systematic Literature Review," Sustainability, vol. 9, no. 9, p. 1602, 2017.

[14] L. Batista, M. Bourlakis, P. Smart, and R. Maull, "In search of a circular supply chain archetype-a content-analysis-based literature review," Prod. Plan. Control, vol. 29, no. 6, pp. 438-451, 2018.
[15] D. S. Rogers and R. S. Tibben-Lembke, Going backwards: Reverse logistics trends and practices. Reverse Logistics Executive Council Pittsburgh, PA, 1999.

[16] S. Lambert, D. Riopel, and W. Abdul-Kader, "A reverse logistics decisions conceptual framework," Comput. Ind. Eng., vol. 61, no. 3, pp. 561-581, 2011.

[17] K. Govindan and H. Soleimani, "A review of reverse logistics and closed-loop supply chains: a Journal of Cleaner Production focus," $J$. Clean. Prod., vol. 142, pp. 371-384, 2017.

[18] A. A. Hervani, M. M. Helms, and J. Sarkis, "Performance measurement for green supply chain management," Benchmarking An Int. J., vol. 12, no. 4, pp. 330-353, 2005.

[19] S. K. Srivastava, "Green supply-chain management: A state-of-the-art literature review," Int. J. Manag. Rev., vol. 9, no. 1, pp. 53-80, 2007.

[20] H. Krikke, J. Bloemhof-Ruwaard, and L. N. Van Wassenhove, "Concurrent product and closed-loop supply chain design with an application to refrigerators," Int. J. Prod. Res., vol. 41, no. 16, pp. 3689-3719, 2003.

[21] J. Q. Frota Neto, J. M. Bloemhof-Ruwaard, J. A. E. E. van Nunen, and E. van Heck, "Designing and evaluating sustainable logistics networks," Int. J. Prod. Econ., vol. 111, no. 2, pp. 195-208, 2008.

[22] K. Khor and Z. Udin, "Impact of Reverse Logistics Product Disposition towards Business Performance in Malaysian E\&E Companies," J. Supply Chain Cust. Relatsh. Manag., vol. 2012, pp. 1-19, 2012.

[23] R. De Angelis, M. Howard, and J. Miemczyk, "Supply chain management and the circular economy: towards the circular supply chain," Prod. Plan. Control, vol. 29, no. 6, pp. 425-437, 2018.

[24] M. R. Chertow, "Industrial Symbiosis: Literature and Taxonomy," Annu. Rev. energy Environ., vol. 25, no. 1, pp. 313-337, 2000.

[25] A. S. Homrich, G. Galvão, L. G. Abadia, and M. M. Carvalho, "The circular economy umbrella: Trends and gaps on integrating pathways," J. Clean. Prod., vol. 175, pp. 525-543, 2018.

[26] N. M. P. Bocken, I. de Pauw, C. Bakker, and B. van der Grinten, "Product design and business model strategies for a circular economy," J. Ind. Prod. Eng., vol. 33, no. 5, pp. 308-320, 2016.

[27] T. Zink, F. Maker, R. Geyer, R. Amirtharajah, and V. Akella, "LCA OF WASTE MANAGEMENT SYSTEMS Comparative life cycle assessment of smartphone reuse: repurposing vs. refurbishment," Int. J. Life Cycle Assess., vol. 19, no. 5, pp. 1099-109, 2014.

[28] K. Richa, C. W. Babbitt, and G. Gaustad, "Eco-Efficiency Analysis of a Lithium-Ion Battery Waste Hierarchy Inspired by Circular Economy," J. Ind. Ecol., vol. 21, no. 3, pp. 715-730, 2017.

[29] European Union, "Directive 2008/98/EC of the European Parliament and of the Council of 19 November 2008 on waste and repealing certain Directives," 2008

[30] J. Potting, M. Hekkert, E. Worrell, and A. Hanemaaijer, "Circular Economy: Measuring innovation in the product chain," 2017.

[31] N. van Buren, M. Demmers, R. van der Heijden, and F. Witlox, "Towards a circular economy: The role of Dutch logistics industries and governments," Sustain., vol. 8, no. 7, pp. 1-17, 2016.

[32] T. Bauer, D. Brissaud, and P. Zwolinski, "Design for High AddedValue End-of-Life Strategies," in Sustainable Manufacturing, Springer, Cham, 2017, pp. 113-128.

[33] N. Jiao and S. Evans, "Business Models for Sustainability: The Case of Second-life Electric Vehicle Batteries," Procedia CIRP, vol. 40, pp. 250-255, 2016.

[34] M. Despeisse, P. D. Ball, S. Evans, and A. Levers, "Industrial ecology at factory level - A conceptual model," J. Clean. Prod., vol. 31, pp. 30$39,2012$. 